\title{
Isokinetic strength of the quadriceps and hamstrings and functional ability of anterior cruciate deficient knees in recreational athletes
}

\author{
Raymond Che Tin Li, Nicola Maffulli, Yuen Cheung Hsu, Kai Ming Chan
}

\begin{abstract}
Objective-To test the hypothesis that increasing the hamstrings and quadriceps (H:Q) isokinetic strength ratio will, in the short term, improve the functional ability of an anterior cruciate ligament (ACL) deficient knee.

Methods-The isokinetic muscular characteristics at a speed of $60^{\circ} \mathrm{s}^{-1}$ and $180^{\circ} \mathrm{s}^{-1}$ of 46 recreational athletes with an arthroscopically confirmed ACL tear were determined using the Cybex II+ isokinetic dynamometer. The variables tested included peak torque, endurance ratio, total work output, and explosive power. Functional ability was scored with the Cincinnati rating system, measuring the severity of pain and swelling, the degree of giving way, and the overall ability to walk, run, ascent and descent stairs, jump and twist.
\end{abstract}

Results-Among all muscular characteristics, the $H: Q$ ratio at $180^{\circ} \mathrm{s}^{-1}$ at $30^{\circ}$ of knee flexion was shown to have the highest correlation to the functional score $(r=$ $0.6249, P<0.001)$. All variables involving hamstring strength were shown to be significantly correlated to the functional ability score $(P<0.01)$, while none of the variables involving quadriceps strength showed significant correlation with the functional ability of the injured knee.

Conclusions-The $H: Q$ ratio is strongly correlated to the functional ability of $A C L$ deficient knees in Chinese recreational athletes. It could be used as an additional measure to guide in the decision making process in the management of $A C L$ deficient knees.

(Br f Sports Med 1996;30:161-164)

Key terms: anterior cruciate ligament; isokinetic strength; hamstring/quadriceps ratio; rehabilitation

Anterior cruciate ligament (ACL) injury in athletes is common, ${ }^{1-3}$ and its management remains controversial. An untreated ACL tear may result in deterioration of knee function with development of rotatory instability, meniscal tears, progressive degeneration of articular cartilage, and eventually posttraumatic arthritis. ${ }^{1}$ 4-8 Some investigators believe that primary repair or reconstruction is mandatory to maintain stability and physiological biomechanics of the knee, enabling athletes to return to their original sports with minimal disruption. ${ }^{9-12}$ Others claim good results with return to high level of sport participation in patients who underwent conservative treatment with a thorough rehabilitation programme. ${ }^{4} 9^{13-15}$ The diversity of such opinions is compounded by the many surgical procedures described. ${ }^{416}$

Strengthening the hamstring muscles has been found to enhance the functional ability of the ACL deficient knee. ${ }^{17-21}$ This is probably due to the fact that, with an overall increase in both the hamstring and quadriceps strength, and increase in the hamstring to quadriceps ratio $(\mathrm{H}: \mathrm{Q})$, antero-lateral subluxation of the tibia may be minimised. ${ }^{22}$

We explored the correlation between the $\mathrm{H}: \mathrm{Q}$ ratio and short term functional outcome among athletes with ACL deficient knees, and assessed whether an increase in $\mathrm{H}: \mathrm{Q}$ ratio approaching 1 resulted in a significant improvement of the functional ability of ACL deficient knees in recreational athletes.

\section{Methods}

Forty six Chinese recreational athletes who attended the sports injury clinic of the Prince of Wales Hospital gave their informed consent to participate in the study. There were 28 males [average age $24 \cdot 2(S D 8 \cdot 4)$ years; average weight $64 \cdot 8(9 \cdot 2) \mathrm{kg}$ ] and 18 females [average age $24 \cdot 1(4 \cdot 24)$ years; average weight $54 \cdot 5(5 \cdot 5)$ $\mathrm{kg}$. All the subjects were recreational athletes (table 1), who were injured during the practice of their sport. They were clinically and arthroscopically diagnosed as having a complete tear of the ACL.

Two weeks after arthroscopy, the quadriceps and hamstring muscle groups were isokinetically tested using the Cybex II+ isokinetic dynamometer at the speeds of $60^{\circ} \mathrm{s}^{-1}$ and $180^{\circ} \mathrm{s}^{-1}$. The main variables tested were peak torque, total work, endurance ratio and average power. The testing apparatus was regularly calibrated according to the manufacturer instructions. ${ }^{23}$ The functional ability of the injured knee was assessed using the

Table 1 Details of the sports practised by the injured athletes

\begin{tabular}{lcc}
\hline Sports & Male & Female \\
\hline Football & 15 & 0 \\
Basketball & 4 & 6 \\
Badminton & 3 & 2 \\
Table tennis & 2 & 1 \\
Volleyball & 2 & 2 \\
Tennis & 1 & 1 \\
Dancing & 0 & 4 \\
Track and field & 1 & 2 \\
Total & 28 & 18 \\
\hline
\end{tabular}

\author{
Polwarth Building, \\ Aberdeen AB9 2ZD \\ United Kingdom. \\ Accepted for publication \\ 2 October 1995 \\ Correspondence to: \\ Nicola Maffulli, \\ Department of Orthopaedic \\ Surgery, University of \\ Aberdeen Medical School, \\ Sports Medicine and \\ physiotherapist \\ Traupatc \\ Hong Kong \\ N Maffulli, visiting \\ Department of \\ Traumatology, \\ Hospital, Hong Kong \\ Y C Hsu, orthopaedic
}


Cincinnati rating $\operatorname{scale}^{24}$ with some modifications to suit the local setting (appendix).

An individual training programme was designed according to the first Cybex test results. Pain relief and control of swelling were achieved using local ice application and interferential therapy. Isokinetic muscle training at the speeds of $60^{\circ} \mathrm{s}^{-1}$ and $180^{\circ} \mathrm{s}^{-1} 10 \mathrm{~min}$ at each speed of training ${ }^{25}$ was performed three times a week for six weeks under the supervision of at least one of the investigators.

The isokinetic training programme aimed to strengthen the quadriceps and hamstring muscle groups, and to establish a high $\mathrm{H}: \mathrm{Q}$ ratio on the injured side, minimising contralateral strength discrepancies. The training programme was adjusted individually according to each athlete's progress, setting the goal of a difference of $15 \%$ or less between quadriceps strength, and an $H: Q$ ratio of the injured knee approaching 1. During the rehabilitation period, patients were required not to participate in any other form of strength training and not to undergo any further medical or physiotherapy treatment to the knee. The patients were informed that they would be excluded from the study if they performed additional training, or received additional medical or physiotherapy care. None did.

The patients were encouraged to report to the medical members of the team should any problems occur. After the rehabilitation period, the second Cybex and Cincinnati rating scale tests were performed. When the results of these two tests were compared, and the percentage changes in muscle characteristics and functional ability were calculated using the formula:

Result of the 2 nd test - result of the 1 st test Result of the 1st test $\times 100$

The functional score percentage change was then correlated with the percentage change between the different isokinetic muscle strength variables. Statistical analysis was performed using the SPSS/PC+ Version 3.0 computer program. ${ }^{26}$ Pearson's correlation and the two tailed paired $t$ test were used. Significance level was set at $\mathrm{P}<0.05$.

\section{Results}

Twenty two athletes injured their dominant knee and 24 injured their non-dominant knee. Thirty two athletes $(70 \%)$ presented with an isolated ACL tear, and $14(30 \%)$ presented with an ACL injury associated with an unstable meniscal tear which was arthroscopically resected. The two groups did not show any significant difference in their isokinetic strength characteristics and functional ability, either before or after rehabilitation. Their data were therefore pooled, and are presented together.

The average score of the first Cincinnati test was $61 \cdot 7(\mathrm{SD} 12 \cdot 2)$, and of the second Cincinnati test, $72 \cdot 5(14 \cdot 1)$, with an average increase of $17.3 \% \quad(P<0.05)$. When the percentage changes of the functional score were tested against the muscle strength
Table 2 Correlation between the muscular characteristics and Cincinnati score of the injured knee

\begin{tabular}{|c|c|c|}
\hline \multicolumn{3}{|c|}{$\begin{array}{l}\text { The following four variables have a significance level of } \\
P<0.001 \text { and } r \text { values ranging from } 0.6249-0.4479 \text { : }\end{array}$} \\
\hline Functional scores & $r$ & $P$ \\
\hline $\begin{array}{l}\text { H:Q } 180 \text { knee } 30 \\
\text { H:Q PKTAE } \\
\text { H } 180 \text { knee } 30 \\
\text { H } 60 \text { knee } 30\end{array}$ & $\begin{array}{l}0.6249 \\
0.4721 \\
0.4646 \\
0.4479\end{array}$ & $\begin{array}{l}<0.001 \\
<0.001 \\
<0.001 \\
<0.001\end{array}$ \\
\hline \multicolumn{3}{|c|}{$\begin{array}{l}\text { The following variables have a significance level of } P<0.01 \\
\text { and } r \text { values ranging from } 0.4383-0.3436 \text { : }\end{array}$} \\
\hline Functional scores & $r$ & $P$ \\
\hline $\begin{array}{l}\text { H:Q } 180 \mathrm{PT} \\
\text { H } 180 \mathrm{PT} / \mathrm{BW} \\
\text { H } 60 \mathrm{PT} \\
\text { H:Q W } \\
\text { H } 60 \mathrm{PT} / \mathrm{BW} \\
\text { H:Q 60 knee } 30 \\
\text { H:Q 180 PT } \\
\text { H PKTAE } \\
\text { H:Q 60 PT }\end{array}$ & $\begin{array}{l}0.4383 \\
0.4240 \\
0.4134 \\
0.4099 \\
0.4026 \\
0.3752 \\
0.3685 \\
0.3531 \\
0.3436\end{array}$ & $\begin{array}{l}<0.01 \\
<0.01 \\
<0.01 \\
<0.01 \\
<0.01 \\
<0.01 \\
<0.01 \\
<0.01 \\
<0.01\end{array}$ \\
\hline $\begin{array}{l}\text { The following vari } \\
\text { increase in functio } \\
\text { Q } 60 \text { PT } \\
\text { Q } 60 \text { knee } 30 \\
\text { Q } 180 \text { knee } 30 \\
\text { Q END }\end{array}$ & $\begin{array}{l}\text { ve no significant } \\
\text { e }(\mathrm{P}>0.05): \\
\text { Q } 60 \mathrm{PT} / \mathrm{BW} \\
\mathrm{Q} 180 \mathrm{PT} / \mathrm{BW} \\
\text { Q 180 PT } \\
\text { H END }\end{array}$ & $\begin{array}{l}\text { tion with the } \\
\text { Q PKTAE } \\
\text { H:Q END }\end{array}$ \\
\hline
\end{tabular}

variables measured, a statistically significant association $(P<0.05)$ was shown with the $\mathrm{H}: \mathrm{Q}$ ratio, measured at $180^{\circ} \mathrm{s}^{-1}$ at $30^{\circ}(r=0.6249$, $\mathrm{P}<0.001)$, with the $\mathrm{H}: \mathrm{Q}$ peak torque acceleration energy $(r=0.4721, \mathrm{P}<0.001)$, and with most of the isokinetic strength variables of the hamstring muscles (see table 2 for details).

On the other hand, no statistically significant association was found with most of the variables relating to the quadriceps (see table 2).

\section{Discussion}

The pattern of ACL deficiency in this series is similar to other reports, ${ }^{4}{ }^{27}$ with a male to female ratio of $1 \cdot 5: 1$.

From the assessment of the isokinetic characteristics of the quadriceps and hamstring muscles and the correlation with the Cincinnati functional score, several points emerged. Firstly, the $\mathrm{H}: \mathrm{Q}$ ratio, when the knee is at $30^{\circ}$ of flexion at a speed of motion of $180^{\circ} \mathrm{s}^{-1}$, shows the highest correlation with the increase in functional scoring. Secondly, all the other characteristics of the hamstrings muscle group show a statistically significant correlation to the functional score. Finally, the quadriceps muscular characteristics show no significant correlation with the functional score.

Based on these points, the working hypothesis that increasing the $H: Q$ ratio at high angular velocities will result in a significant improvement of the functional ability of an ACL deficient knee is proven. The converse is also true; thus athletes with a low $\mathrm{H}: \mathrm{Q}$ ratio will have low functional ability.

In most studies, only peak torque values, an expression of maximum strength at a set angular velocity, are given, and other variables are not expressly stated. ${ }^{28-30}$ When planning a rehabilitation programme for the hamstring muscle group, endurance should be trained as well, and measures of this variable should also be included. ${ }^{31}$ Accordingly, when trying to achieve an $\mathrm{H}: \mathrm{Q}$ ratio of 1 , a rehabilitation 
programme should also try to produce a significant increase in the endurance ratio of the quadriceps and of the hamstring, aiming for it to equal 1. Furthermore, the angle of occurrence of the peak torque should also be given. ${ }^{32-34}$

On the basis of the evidence produced, hamstring training should be one of the main issues of rehabilitation of an ACL deficient knee, at least in the short term. Training of all muscle strength attributes, including peak torque strength, power, endurance, and peak torque acceleration energy, should be planned.

The quadriceps muscle characteristics have been shown to have very little correlation with the functional ability of the ACL deficient knee. $^{35} 36$ However, maintaining quadriceps strength at a level of at least $85 \%$ of that of the uninjured knee is essential for the general functioning of the knee. ${ }^{35} 36$ Since most studies showed no significant difference in the bilateral knee muscle strength measured isokinetically, ${ }^{28} 30^{37-41}$ bilateral muscle strength symmetry should be maintained in the physiological range. However, in order to achieve a high $H: Q$ ratio in the ACL injured knee at the same time, one should consider allowing a low percentage of bilateral quadriceps discrepancy, provided the quadriceps muscle is trained early enough to avoid atrophy, as studies have shown that the quadricipital muscle group of an ACL injured knee is more prone to develop atrophy than the hamstrings. ${ }^{18}{ }^{22}$ Nyland $e t ~ a l$, in a case study of a rehabilitation programme on the knee function following an ACL reconstruction, reported a residual $11 \%$ strength deficit even after one year of rehabilitation. ${ }^{29}$ Campbell et al reported that the average torque of knees operated for ACL deficiency was 10-12\% less than that of normal knees. ${ }^{31}$ Costill et al also reported a $20 \%$ torque deficit in knees operated for ACL deficiency. ${ }^{41}$ Costain et al remarked that rehabilitating an injured knee to $80 \%$ of the level of the normal knee was probably inadequate, particularly if the patients are athletes returning to competition. ${ }^{39}$ It is therefore essential to maintain the quadriceps of the ACL injured knee at a level of at least $85 \%$ of the uninjured one to ensure the patients return to sports participation and are safe enough to compete in the future.

There are certainly some limitations to our study, mainly resulting from the relatively small series of patients and the short period of follow up. One should also take into consideration intraindividual variation in isokinetic muscle testing, and the subjectivity of the Cincinnati rating system. Our study did not show significant differences between athletes with isolated ACL tears and those with an ACL tear associated with a meniscal tear. This could be due either to the small size of our study sample, to the short length of follow up, or to a combination of these factors. It has been shown that meniscectomy results in secondary degenerative changes to the involved compartment of the knee, resulting in a long term decrease in functional abilities. ${ }^{42}$ We are planning a long term study to determine whether the favourable $\mathrm{H}: \mathrm{Q}$ ratio has been maintained, and, if so, it still shows such a significant correlation with the functional ability of the knee. Also, it would be interesting to see whether any differences develop between athletes with an isolated ACL tear and those in whom an ACL tear was associated with an unstable meniscal tear requiring resection.

Despite these limitations, in the short term the $H: Q$ ratio is strongly correlated with the functional ability of ACL deficient knees in Chinese recreational athletes. Together with additional criteria, such as proprioception, ${ }^{44} 45$ the $H: Q$ ratio could be used as an additional measure to guide in the decision making process in the management of ACL deficient knees.

\section{Appendix}

\section{The modified Cincinnati rating scale}

SYMPTOMS (50 POINTS)

Pain

20 No pain, normal knee

16 Occasional pain with strenuous sports or heavy work

12 Occasional pain with recreational sports or moderate work, frequently brought on by sports

8 Pain usually brought on by sports, light recreational activities or moderate work

4 Pain is a significant problem with activities as simple as walking and standing. Unable to do sports

0 Pain present all the time, not relieved with rest

\section{Swelling}

10 No swelling, normal knee

8 Occasional swelling with strenuous sports or heavy work

4 Swelling limits sports and moderate work

2 Swelling brought on by simple walking activities and light work

0 Severe problem all the time

\section{Giving way}

20 No giving way, normal knee

16 Occasional giving way with strenuous sports or heavy work

12 Occasional giving way with light recreational activities or moderate work, not able to twist on cut suddenly

8 Giving way limits sports and moderate work

4 Giving way with simple walking activities and light work

0 Severe problem with simple walking activities

FUNCTION (50 POINTS)

Overall activity level

20 No limitation, normal knee

16 Perform sports including vigorous activities, but at a lower performance level

12 Light recreational activities possible with rare symptoms, more strenuous activities cause problems

8 No sports or recreational activities possible, walking possible with rare symptoms

4 Walking activities of daily living cause moderate symptoms

0 Walking activities of daily cause severe problems, persistent symptoms

\section{Walking}

10 Normal, unlimited

$8 \mathrm{Slight/mild} \mathrm{problem}$

6 Moderate problem: smooth surface up to $800 \mathrm{~m}$

4 Severe problem: only two to three blocks possible

2 Severe problem: requires walking aids 
Stairs

10 Normal, unlimited

$8 \mathrm{Slight} / \mathrm{mild}$ problem

6 Moderate problem: 10-15 steps possible

4 Severe problem: requires banister, support

2 Severe problem: only one to five steps possible

\section{Running activity}

5 Normal, unlimited: fully competitive, strenuous

4 Slight/mild problem: run half speed

3 Moderate problem: only $2-4 \mathrm{~km}$ possible

2 Severe problem: only one to two blocks possible

1 Severe problem: only a few steps

\section{Jumping or twisting activities}

5 Normal, unlimited, fully competitive

4 Slight/mild problem: some guarding, but sports possible

3 Moderate problem: gave up strenuous sports

2 Severe problem: affects all sports, must constantly guard

1 Severe problem: only light activity possible

1 Sandberg R, Balkfors B. The durability of anterior cruciate ligament reconstruction with the patellar tendon. $\mathrm{Am} \mathcal{F}$ Sports Med 1988;4:341-3.

2 Kaplan N, Wickiewing TL, Warren RF. Primary surgical treatment of anterior cruciate ligament rupture. A long term follow-up study. Am $\mathcal{F}$ Sports Med 1990;18:354-8.

3 Torg JS, Comad W, Kalen V. Clinical diagnosis of anterior cruciate ligament instability in athletes. $\mathrm{Am} \mathcal{F}$ Sports $\mathrm{Med}$ 1967;4:84-93.

4 Glove TP, Miller SJ, Kent BE, Sanfore TJ, Garrick JG. Non-operative treatment of torn anterior cruciate Non-operative treatment of torn anterior cru
ligament. $₹$ Bone foint Surg $[\mathrm{Am}]$ 1983;65A:184-92.

5 McDaniel WJ, Dameron TB. The untreated anterior cruciate ligament rupture. Clin Orthop 1983;172:158-63.

6 Feagin JA, Colonel OO, Curl WW. Isolated tear of the anterior cruciate ligament: 5-year follow-up study. $A m \mathcal{J}$ Sports Med 1976;14:95-100

7 McDaniel WJ, Dameron TB. Untreated ruptures of the anterior cruciate ligament. $f$ Bone foint Surg [Am] 1980;62A:696-705.

8 Marshall JL, Rubin RM, Wang JB, Fetto JF, Arnoczky SP. The anterior cruciate ligament. The diagnosis and treatment of its injuries and their serious prognostic implications. Orthop Rev 1978;7:35-46.

9 Marshall JL, Rubin RM. Knee ligament injuries. A diagnostic and therapeutic approach. Orthop Clin North Am 1977;8:641-68.

10 Marshall JL, Warren RF, Wickiewicz. Primary surgical treatment of anterior cruciate ligament lesion. Am 7 Sports Med 1982;10:103-7.

11 O'Donoghue DH. Reconstruction for medial instability of the knee. Technique and results of six cased. $\mathcal{f}$ Bone foint Surg $[A m]$ 1973;55A:941-55.

12 Nicholas JA. The five in one reconstruction for anteromedial instability of the knee. Indications, technique, and the results in fifty-two patients. F Bone foint Surg [Am] 1973;55A:899-922.

13 Chick RR, Jackson DW. Tears of the anterior cruciate ligament in young athletes. $f$ Bone foint Surg [OO] 1978;10:970-3.

14 Nicholas JA, Strizak AM, Veras G. A Study of thigh muscle weakness in different pathological states of the lower extremity. Am $\mathcal{F}$ Sports Med 1976;4:241-8.

15 Paulos L, Noyes FR, Grood E, Butler DL. Knee rehabilitation after anterior cruciate ligament reconstruction and repair. Am $\mathcal{F}$ Sports Med 1981;9:140-7.

16 Clanton TO, Delee JC, Sanders B, Neidre A. Knee ligamen injuries in children. $\mathcal{f}$ Bone foint Surg [Am] injuries in children.

17 Highgenboten CL, Jackson AW, Meske NB. Concentric and eccentric torque comparisons for knee extension and flexion in young adult males and females using the

18 Vegso JJ, Genuario SE, Torg JS. Maintenance of hamstrings strength following knee surgery. Med Sci Sports Exerc 1985;17:376-9.
19 Arvidsson I, Eriksson E. The crucial ligaments. Counteracting muscle atrophy after $A C L$ injury: scientific bases for a rehabilitation program. Edinburgh: Churchill Livingstone, rehabilitation
$1987: 454$.

20 Engle RP. Hamstring facilitation in anterior instability of the knee. Athletic Training 1988;23:226-9.

21 Galway HR, Macintosh DL. The lateral pivot shift: a symptom and sign of anterior cruciate ligament insufficiency. Clin Orthop 1980;147:45-51.

22 Kannus P. Ratio of hamstring to quadriceps femoris muscles' strength in the anterior cruciate ligament insufficient knee. Relationship to long term recovery. Phys Ther 1988;6:961-5.

23 Lumex Inc. Cybex II + service and parts manual. New York: Division of Lumex inc, 1985.

24 Noyes FR, McGinniss GH, Mooar LA. Functional disability in the anterior cruciate insufficient knee syndrome. Review of knee rating systems and projected risk factors in determining treatment. Sports Med 1984;1:278-302.

25 Wilk KE, Andrews JS. The effect of pad placement and angular velocity on tibia displacement during isokinetic

26 SPSS PC+V3.0. Statistical package for the social sciences. Chicago: SPSS, 1989.

27 Hawkins RI, Misamore GW, Merritt TR. Follow-up of the acute nonoperated isolated anterior cruciate ligament tear. Am $\mathcal{F}$ Sports Med 1986;14:205-10.

28 Hageman PA, Gillaspie DM, Hill LD. Effects of speed and limb dominance on eccentric and concentric isokinetic testing of the knee. F Orthop Sports Phys Ther 1988; 10:59-65.

29 Nyland JA, Canic DP, Ray M, Duly MJ. A case study of an accelerated rehabilitation program on knee function following anterior cruciate ligament reconstruction. $\mathcal{f}$ Sports Rehabil 1993;2:53-62.

30 Wyatt MP, Edwards AM. Comparison of quadriceps and hamstring torque values during isokinetic exercise. $f$ Orthop Sports Phys Ther 1981;3:202-10.

31 Campbell DE, Glenn W. Foot-pounds of torque of the normal knee and the rehabilitated postmeniscectomy knee. Phys Ther 1979;59:418-21.

32 Elmqvist LG, Lorentzon R, Largstrom M, Fugl-Meyer AR. Reconstruction of the anterior cruciate ligament. $A m \mathcal{F}$ Sports Med 1988;16:455-62.

33 Renstrom P, Arm SW, Stanwyck TS, Johnson RJ, Pope MH. Strain within the anterior cruciate ligament during hamstring and quadriceps activity. $A m \tilde{f}$ Sports Med 1986;14:83-7.

34 Hirokawa S, Solomomow M, Lu Y, Lou ZP, D'Ambrosia R. Anterior-posterior and rotational displacement of the tibia elicited by quadriceps contraction. Am $\mathcal{F}$ Sports Med 1992;20:299-306.

35 Howell SM. Anterior tibia translation during a maximum quadriceps contraction: is it clinically significant? $\mathrm{Am} \mathcal{F}$ Sports Med 1990;18:573-8.

36 Hagood S, Solomonow H, Baratta $R$, Zhou B, D'Ambrosia R. The effect of joint velocity on the contribution of the antagonist musculature to knee stiffness and laxity. Am $\mathcal{F}$ Sports Med 1990;18:182-7.

37 Chmelar RP, Shultz BB, Ruhing RO, Fitt SS, Johnson MS. Isokinetic characteristic of the knee in female, professional and university, ballet and modern dancers. F Orthop Sports Phys Ther 1988;9:410-8.

38 Thomas LE. Isokinetic torque levels of adult females: effects of age and body size. $₹$ Orthop Sports Phys Ther 1984; of age

39 Costain $R$, Williams AK. Isokinetic quadriceps and hamstring torque level of adolescent, female soccer players. F Orthop Sports Phys Ther 1984;5:196-200.

40 Tippelt SR. Lower extremity strength and active range of motion in college baseball pitcher. A comparison between stance leg and kick leg. F Orthop Sports Phys Ther 1986;8:10-4.

41 Costill DL, Finle WJ, Hakansiy AJ. Muscle rehabilitation after knee surgery. Phys Sports Med 1977;5:71-4.

42 Neyret P, Donell ST, Dejour, H. Result of partial meniscetomy related to the state of anterior cruciate ligament. $\mathcal{F}$ Bone foint Surg [Br] 1993;75B:36-40.

43 Neyret P, Donell ST, Dejour D, Dejour H. Partial meniscectomy and anterior cruciate ligament rupture in soccer players. A study with a minimum of 20 years followup. Am $\mathcal{F}$ Sports Med 1993;21:455-60.

44 Barrack RI, Skinner HB, Backlay SL. Proprioception in the anterior cruciate ligament knee. Am $\Im$ Sports Med 1989; 17:1-6.

45 Barrett DS. Proprioception and function after anterior cruciate reconstruction. F Bone foint Surg $[B r]$ 1991; 73B:833-7. 